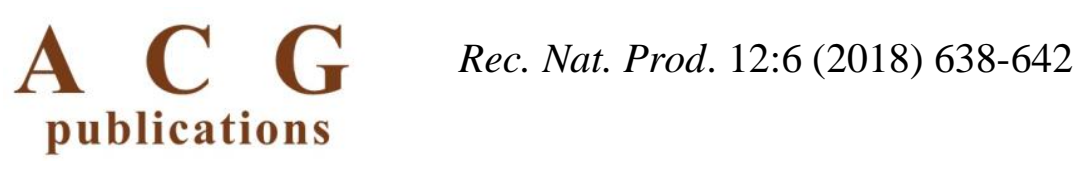

records of natural products

\title{
Comparisons of Chemical and Biological Studies of Essential Oils of Stem, Leaves and Seeds of Zanthoxylum alatum Roxb growing wild in the State of Azad Jammu and Kashmir, Pakistan
}

\author{
Muhammad Irshad ${ }^{\oplus 1^{*}}$, Shahid Aziz ${ }^{\oplus 2}$, Habib-ur-Rehman ${ }^{\oplus 2}$, Muhammad \\ Naeem Ahmed ${ }^{\oplus 3}$, Ghulam Asghar ${ }^{\oplus 4}$, Muhammad Akram ${ }^{\oplus 5}$ and \\ Muhammad Shahid ${ }^{\oplus 6}$ \\ ${ }^{I}$ Department of Chemistry, University of Kotli Azad Jammu \& Kashmir (UoKAJK), 11100 AJK \\ Pakistan \\ ${ }^{2}$ Department of Chemistry, Mirpur University of Science and Technology (MUST), Mirpur- \\ 10250(AJK), Pakistan \\ ${ }^{3}$ Department of Chemistry, University of Azad Jammu \& Kashmir Muzaffarabad (UAJK) Pakistan \\ ${ }^{4}$ Department of Physics, University of Poonch, Rawalakot, 12350, AJK Pakistan \\ ${ }^{5}$ Department of Eastern Medicine, Directorate of Medical Sciences, Government College University, \\ Faisalabad, Pakistan \\ ${ }^{6}$ Department of Biochemistry, University of Agriculture, Faisalabad-38040, Pakistan
}

(Received November 30, 2017; Revised February 08, 2018; Accepted February 12, 2018)

\begin{abstract}
The fresh plant material of stem, leaves and seeds of Zanthoxylum alatum Roxb (Rutaceae) collected at high altitude of District Kotli, the State of Azad Jammu \& Kashmir and subjected to Clevenger type hydro distillation for the extraction of essential oils. The essential oils were characterized by using gas chromatography-mass spectrometry (GC-MS) technique. Twenty five components have been identified from the stem yielded about $95.8 \%$ of the total essential oils, the major constituents were Terpinen-4-ol $(30.47 \%), \beta$ Terpenene (16.16\%), eighteen components identified from the leaves which yields about $89.08 \%$ of the oil, Tridecanone (25\%), Isohexane (21.4\%), Eucalyptol $(8.5 \%)$ and Linalool $(7.21 \%)$ were the major constituents. From the seeds of Z. alatum twenty components have been identified which yielded about $98.5 \%$ of the oil; major components were Linalool (45\%), Isohexnae (38\%), Methyl-10-octadecanoate (6.25\%). The essential oils show significant antioxidant, antimicrobial activities. The essential oils of $Z$. alatum are expected to be used as traditional herbal system of medicine.
\end{abstract}

Keywords: Zanthoxylum alatum Roxb; essential oil; antioxidant and antimicrobial. (C) 2018 ACG Publications. All rights reserved.

\section{Plant Source}

Zanthoxylum alatum has been collected from form District Kotli at High altitude of the State of Azad Jammu and Kashmir in July-September, 2009. The plant was identified and authenticated by Dr. Tariq Habib Assistant Professor, the plant taxonomist at the Department of Botany, University of Azad Jammu and Kashmir Muzaffarabad. A voucher specimen (AJKBOT-425) has been deposited at the Laboratory of Botany, Department of Botany, University of Azad Jammu and Kashmir and Muzaffarabad.

\footnotetext{
${ }^{*}$ Corresponding author: E Mail: chemist_q2005@yahoo.com
} 


\section{Previous Studies}

The genus Zanthoxylum L. (Rutaceae) consists of more than 200 trees and shrubs which included in the tribe Zanthoxyleae of the Rutaceae. Zanthoxylum species are mainly pan-tropical in distribution. Zanthoxylum alatum is a curative shrub, locally known as "Timber" and is distributed in moist and hilly regions of Pakistan [1]. The powdered material of the seed of Z. alatum has been used as spice and also be used as aromatic tonic, dyspepsia, stomachic, cholera and also for fever [2]. The fruits, thorns and branches are considered to be stomachic, carminative and are also used as a tonic for toothache. In India the bark and fruit of Z. alatum is used to teat the skin related diseases, anorexia, abdominal pain, ataxia and warm infestation in Ayurveda practice [3] identified 56 constituents, representing $99.5 \%$ of the oil. Linalool $(71 \%)$, limonene $(8.2 \%)$, phellandrene $(5.7 \%)$ and $(\mathrm{Z})$ methylcinnamate $(4.9 \%)$ were the main constituents. It was also suggested that the seeds of $Z$. alatum could be used as a commercial source for the isolation of linalool.

It has also been reported that linalool (56.10\%) and methyl cinnamate $(19.73 \%)$ are major constituents of the essential oils of $Z$. alatum that completely inhibited the growth of a toxigenic strain of $A$. flavus as well as aflatoxin $\mathrm{B}(1)$ secretion at various concentrations[4].

The review of literature suggests that the essential oil of Zanthoxylum armantum has good antimicrobial potential [5].

Ethanol extract of $Z$. alatum showed excellent antioxidant activity against two pro-oxidants in tissues. However, it was more effective against sodium nitroprusside (SNP) induced inhibition as compared to $\mathrm{Fe}^{2+}$ induced thiobarbituric acid reactive substances (TBARS) in liver brain and kidney. Rats which are overloaded with iron exhibited toxic effects such as cardiomyopathy, hepatocellular hypertrophy, splenic white pulp atrophy, pancreatic atrophy and hemosiderosis in the liver, heart, pancreas and endocrine glands. Z. alatum extract offered protection on tissues such as liver brain and kidney confirmed the antioxidant activity of extract which indicated its use in accidental intoxications resulted from the overload with single nucleotide polymorphism (SNP) [6].

\section{Present Study}

Zanthoxylum alatum was collected from the Kotli hills of Azad Jammu and Kashmir. The seeds were collected at the end of August when they were fully ripened and the stem and leaves were collected in July. Plant samples were dried in shade for three to five days. Detail of experimental procedures reported here in are given in supporting information file.

Present study on $Z$. alatum is to compare the results of the essential oils of stem, leaves and seeds of Z. alatum. The essential oil of stem, leaves and seeds was subjected for their GC-MS analysis which revealed the presence of 25 components from the stem of this plant which yields about $94 \%$ of the total essential oils, the major constituents were terpinen-4-ol (30.47\%), $p$-mentha-1 (7\%), 3-diene $(16.16 \%), \beta$-thujene $(8.78 \%)$ and methyl-10-octadecanoate $(6.7 \%), 18$ components have been identified from the leaves of this plant yields about $87 \%$ of the oil, tridecanone (25\%), isohexane (21.4\%), eucalyptol $(8.5 \%)$ and linalool $(7.21 \%)$ were the major constituents and 20 components have been identified from the seeds of which yields about $98.4 \%$ of the oil, major components were linalool $(45 \%)$, isohexane (38\%), methyl-10-octadecanoate (6.25\%) and n-hexadecanoic acid (6.0\%). The constituents are shown in Table-1. It has been investigated that sixteen component from leaves and seventeen components from seeds of this plant were common to stem essential oil. Among the total essential oils thirteen were common to stem, leaves and seeds of $Z$. alatum. Previous results on this plant revealed that there is no work has been carried out so for to compare the essential oils composition of stem, leaves and seeds material. In our investigation on this plant also revealed that isohexane is the major component in the seeds and leaves also seems to be appearing first time from $Z$. alatum stem, leaves and seeds. 
Table 1. Composition \% of the essential oil of stem, leaves and seeds of Zanthoxylum alatum

\begin{tabular}{|c|c|c|c|c|c|c|c|}
\hline \multirow[t]{2}{*}{${ }^{\mathrm{a} C o m p o n e n t s}$} & \multirow[t]{2}{*}{${ }^{\mathbf{b}} \mathbf{R I}$} & \multirow[t]{2}{*}{${ }^{{ }^{\mathbf{c}} \mathbf{R I}}$} & \multirow[t]{2}{*}{ Ref. } & \multicolumn{3}{|c|}{ Composition \% } & \multirow[t]{2}{*}{${ }^{\mathrm{d}}$ Identification } \\
\hline & & & & stem & leaves & seeds & \\
\hline Isohexane & 570 & 568 & [7] & 4.72 & 21.4 & 38.27 & RI, MS \\
\hline Methyl cyclopentane & 635 & 623 & [7] & 1.20 & 1.03 & 2.74 & RI, MS \\
\hline Cyclohexane & 662 & 665 & [8] & 0.70 & 0.89 & 1.47 & RI, MS \\
\hline Heptane & 700 & 700 & [9] & 1.03 & 1.17 & 2.04 & RI, MS \\
\hline$\alpha$-Thujene & 930 & 928 & {$[10]$} & 0.30 & - & 0.1 & RI, MS \\
\hline$\alpha$-Pinene & 939 & 936 & [10] & 0.29 & 0.5 & 0.2 & RI, MS \\
\hline$\beta$-Thujene & 972 & 966 & [11] & 8.78 & 0.32 & - & RI, MS \\
\hline$\beta$-Myrcene & 986 & 990 & [9] & 2.22 & - & - & RI, MS \\
\hline$\beta$-Pinene & 988 & 975 & [11] & 0.35 & 3.20 & 0.1 & RI, MS \\
\hline 4-Carene & 1009 & 1012 & [10] & 0.394 & - & - & RI, MS \\
\hline$m$-Cymene & 1017 & 1012 & [12] & 2.07 & - & $\mathrm{t}$ & RI, MS \\
\hline$\alpha$-Terpinene & 1018 & 1016 & [11] & 0.60 & 1.2 & 0.1 & RI, MS \\
\hline Eucalyptol & 1031 & 1033 & [13] & - & 8.50 & 0.8 & RI, MS \\
\hline$\beta$-Terpenene & 1049 & 1056 & {$[15]$} & 16.16 & - & - & RI, MS \\
\hline$\gamma$-Terpinene & 1060 & 1058 & [9] & 1.43 & 1.2 & 0.5 & RI, MS \\
\hline$\alpha$-Terpinolene & 1090 & 1086 & [12] & 0.62 & 2.3 & - & RI, MS \\
\hline Linalool & 1097 & 1098 & [9] & 1.47 & 7.21 & 30.6 & RI, MS \\
\hline Cis- $\beta$-Terpineol & 1142 & 1143 & {$[12]$} & 6.06 & 4.20 & - & RI, MS \\
\hline Terpinen-4-ol & 1177 & 1174 & [11] & 30.47 & 1.01 & 1.04 & RI, MS \\
\hline Cryptone & 1180 & 1183 & [12] & 0.64 & - & 0.4 & RI, MS \\
\hline$\alpha$-Terpineol & 1189 & 1194 & [9] & 1.55 & 5.3 & 0.1 & RI, MS \\
\hline Cis-Piperitol & 1211 & 1205 & [14] & 1.39 & - & - & RI, MS \\
\hline Caryophyllene & 1400 & 1419 & [12] & 0.60 & - & - & RI, MS \\
\hline$\beta$-Caryophyllene & 1455 & 1418 & [10] & 3.2 & 2.3 & 4.0 & RI,MS \\
\hline Caryophyllene oxide & 1578 & 1581 & [11] & 3.6 & - & 2.50 & RI, MS \\
\hline Tridecanone & 1905 & 1905 & [12] & - & 25 & 4.0 & RI, MS \\
\hline n-Hexadecanoic acid & 1971 & 1971 & {$[10]$} & - & - & 6.0 & RI, MS \\
\hline Methyl-10-octadecanoate & 2139 & 2130 & {$[16]$} & 6.7 & 2.35 & 6.25 & RI, MS \\
\hline Monoterpene hydrocarbons & & & & 31.1 & 8.72 & 1 & \\
\hline Oxygenated monoterpenes & & & & 41.58 & 26.22 & 33.0 & \\
\hline Sesquiterpene hydrocarbons & & & & 3.8 & 2.3 & 4.0 & \\
\hline Oxygenated Sesquiterpene & & & & 5.67 & - & 2.50 & \\
\hline Others & & & & 13.65 & 51.84 & 58.0 & \\
\hline Total & & & & 95.8 & 89.08 & 98.5 & \\
\hline
\end{tabular}

${ }^{\mathrm{a} C o m p o n e n t s ~ l i s t e d ~ i n ~ o r d e r ~ o f ~ e l u t i o n ~ f r o m ~ H P-5 ~ M S ~ c o l u m n ~}$

${ }^{b} \mathrm{RI}$ : Calculated retention index

${ }^{\mathrm{C}} \mathrm{RI}$ : Reported Retention Index

MS: Mass spectrometry

The antioxidant activity of the essential oils of $Z$. alatum was assessed by using DPPH radical scavenging method is shown in Table 2. Free radical scavenging capacity of the essential oils was noted to be increased in a concentration dependent manner. The extracts of stem, leaves and seeds of Z. alatum exhibited DPPH free radical scavenging activity with $\mathrm{IC}_{50} 50.08 \pm 0.12,39.09 \pm 0.06,48.67$ \pm 0.05 respectively. Essential oils of leaves exhibited maximum percentage inhibition while essential oil of stem showed minimum percentage inhibition of DPPH, $\mathrm{IC}_{50}(\mu \mathrm{g} / \mathrm{mL})$. The essential oil extracts of stem, leaves and seeds show DPPH inhibition percentage of oils higher as compared to synthetic $\operatorname{BHT}(18.5 \pm 0.1 \%)$. 
Z. alatum extracts of essential oils of stem, leaves and seeds exhibited inhibition percent of linoleic acid $48.05 \pm 0.29,94.49 \pm 0.05,44.8 \pm 0.4$ respectively. Essential oils of leaves exhibited the highest percentage inhibition (94.49) while the seeds extract exhibited comparatively lower value of percentage inhibition of linoleic acid system as compared to synthetic BHT $(77.00 \pm 3.2 \%)$.

The essential oil extracts of stem of $\mathrm{Z}$. alatum exhibited excellent antibacterial activity against $S$. aureus, E. coli and $P$. multocida while the essential oils of seeds exhibited excellent activity against B. subtilis and leaves showed excellent activities against B. subtilis, P. multocida, S. aureus. Among the three extracts stem, seeds and leaves of $Z$. alatum, essential oils from the leaves showed relatively high activities against all of the tested bacterial strain. The antibacterial activities of essential oils have been shown in Table 3.

The essential oils of stem of $Z$. alatum showed maximum antifungal activity against $G$. lucidum and minimum against $R$. solani while the essential oil extrct of seeds exhibited maximum activity against $G$. lucidum, $R$. solani and minimum against $A$. flavus and essential oils of leaves showed maximum activity against $R$. solani, G. lucidum, and minimum activity against, A. niger, A. flavus. The antifungal activities of these extracts have been shown in Table 3 . From the results of antimicrobial activities it is concluded that the essential oils from the leaves of $Z$. alatum exhibited relatively strong antimicrobial activities as compared to the essential oils of stem and seeds.

Table 2. Antioxidant activities of essential oil of stem, seeds and leaves of Zanthoxylum alatum by DPPH radical scavenging and linoleic acid inhibition assay

\begin{tabular}{lcccc}
\hline Antioxidant assay & Stem & Leaves & Seeds & BHT \\
\hline $\mathrm{DPPH}_{\mathrm{IC}}(\mu \mathrm{g} / \mathrm{mL})$ & $50.08 \pm 0.12$ & $39.09 \pm 0.06$ & $48.67 \pm 0.05$ & $18.5 \pm 0.1$ \\
$\beta$-carotene-Linoleic Acid $(\%)$ & $48.05 \pm 0.29$ & $94.49 \pm 0.05$ & $44.8 \pm 0.04$ & $77.00 \pm 3.2$
\end{tabular}

Table 3. Antimicrobial activity in terms of minimum inhibitory concentration (MIC) of essential oils of Zanthoxyllum alatum stems, leaves and seeds $(\mu \mathrm{g} / \mathrm{mL})$

\begin{tabular}{llllll}
\hline & Stem & Leaves & Seeds & Amoxillin & Fluconazole \\
\hline B. subtilis & $59.3 \pm 2.7$ & $3.83 \pm 0.03$ & $3.6 \pm 0.01$ & $25.03 \pm 0.25$ & \\
S. aureus & $31.4 \pm 2.2$ & $72.93 \pm 7.0$ & $5.76 \pm 0.05$ & $12.51 \pm 0.10$ & \\
E. coli & $49.5 \pm 2.0$ & $23.15 \pm 2.3$ & $5.4 \pm 0.05$ & $37.96 \pm 0.37$ & \\
P. multocida & $10.2 \pm 1.1$ & $5.75 \pm 0.05$ & $43.59 \pm 4.3$ & $25.03 \pm 0.25$ & \\
A. niger & $56.5 \pm 0.00$ & $62.01 \pm 0.03$ & $41.7 \pm 0.01$ & & $92.3 \pm 0.00$ \\
A. flavus & $42.0 \pm 0.5$ & $54.0 \pm 0.05$ & $32.5 \pm 0.3$ & & $58.5 \pm 1.2$ \\
G. lucidum & $23.45 \pm 0.4$ & $4.7 \pm 0.01$ & $5.5 \pm 0.05$ & & $76.4 \pm 0.8$ \\
R. solani & $80.7 \pm 0.9$ & $5.00 \pm 0.07$ & $7.2 \pm 0.05$ & & $64.2 \pm 5.0$ \\
\hline
\end{tabular}

Values are mean \pm standard deviation of three different samples of essential oil of Zanthoxyllum alatum, stem, leaves and seeds

\section{Acknowledgments}

We are very thankful to HEC Pakistan for providing financial support and department of Biochemistry, University of Agriculture, Faisalabad, Pakistan to provide the bioassay facilities of essential oils samples.

\section{Supporting Information}

Supporting Information accompanies this paper on http://www.acgpubs.org/RNP

\section{ORCID}

Muhammad Irshad: 0000-0001-9657-7688 
Shahid Aziz: 0000-0003-2744-6697

Habib-ur-Rehman: 0000-0001-8534-4563

Muhammad Naeem Ahmed: $\underline{0000-0002-5559-1763}$

Ghulam Asghar: 0000-0002-7723-2833

Muhammad Akram: 0000-0001-7863-8803

Muhammad Shahid: 0000-0001-7484-1281

\section{References}

[1] S.M. Majid, M. Arshad, E. Ahmad and M. Ishaque (2004). Ethno photo- therapies for the treatment of various diseases by the local people of selected areas of NWFP (Pakistan), Pakistan J. Biol. Sci. 7, 1104-1108.

[2] P.K. Rout, S.N. Naik, Y.R. Rao, G. Jadeja and R.C. Maheshwari (2007). Extraction and composition of volatiles from Zanthoxylum rhesta: Comparison of sub critical $\mathrm{CO} 2$ and traditional processes, $J$. Supercrit. Fluids. 42, 334-341.

[3] J. Neetu, S.K. Srivastava, K.K. Aggarwal, S. Ramesh and K. Sushil (2001). Essential oil composition of Zanthoxylum alatum seeds from northern India, Flavour Fragr. J. 16, 408-410.

[4] B. Prakash, P. Singh, P.K. Mishra, and N.K. Dubey, (2012). Safety assessment of Zanthoxylum alatum Roxb. essential oil, its antifungal, antiaflatoxin, antioxidant activity and efficacy as antimicrobial in preservation of Piper nigrum L. fruits, Int. J. Food. Microbiol. 153, 183-191.

[5] A. Saini (2013). Evaluation of seed oil of Zanthoxylum armatum for antimicrobial activity, Drug Discov. Ther. 1 (5), 17-20.

[6] F. Batool, S.M. Sabir, J.B. Asad, H. Shah, Z. F. Saify and Ahmed S.D (2010). Evaluation of antioxidant and free radical scavenging activities of fruit extract from Zanthoxylum alatum, a commonly used spice from Pakistan, Pak. J. Bot. 42, 4299-4311.

[7] P. Rotsatchakul, W. Visesanguan, T. Smitinont and S. Chaiseri (2009). Changes in volatile compounds during fermentation of nham (Thai fermented sausage), Int. Food Res. J. 16, 391-414.

[8] W.C. and C. Song (1995). Temperature-programmed retention indices for GC and GC-MS analysis of coal- and petroleum-derived liquid fuels, Fuel 74, 1436-1451.

[9] K.L. Goodner (2008). Practical retention index models of OV-101, DB-1, DB-5, and DB-Wax for flavor and fragrance compounds, LWT. 41,951-958.

[10] P. Lai, H. Rao and Y. Ga (2018). Chemical composition, cytotoxic, antimicrobial and antioxidant activities of essential oil from Anthriscus caucalis M. Bieb grown in China, Rec. Nat. Prod. 12, 290294.

[11] C. Capetanos, V. Saroglous, P.D. Marin, A. Simic and H.D Skaltsa. 2007. Essential oil analysis of two endemic Eryngium species from Serbia, J. Serb.Chem. Soc. 72, 961-965.

[12] V.I. Babushok, P.J. Linstrom, and I.G. Zenkevichb. Retention indices of frequently reported compunds of plants essential oils, National Institute of Standards and Technology, Gaithersburg, Maryland 20899, USA, 20119.

[13] H.R. Juliani, J.A. Zygadlo, R. Scrivanti, E.D. Sota and J.E. Simon (2004.) The essential oil of Anemia tomentosa (Savigny) Sw. var. anthriscifolia (Schrad.) Mickel, Flavour Fragr. J. 19, 541-543.

[14] A. Maggio, S. Rosselli, M. Bruno, V. Spadaro, F. M. Raimondo and F. Senator (2012). Chemical composition of essential oil from italian populations of Artemisia alba Turra (Asteraceae), Molecules 17, 10232-10241.

[15] Y. Zhao, J. Li, Y. Xu, H. Duan, W. Fan and G. Zhao (2008). Extraction, preparation and identification of volatile compounds in Changyu XO brandy, Chin. J. Chromatogr. 26, 212-222.

[16] V. Saroglou, N. Dorizas, Z. Kypriotakis and H.D. Skaltsa (2006). Analysis of the essential oil composition of eight Anthemis species from Greece, J. Chromatogr. A. 1, 313-322.

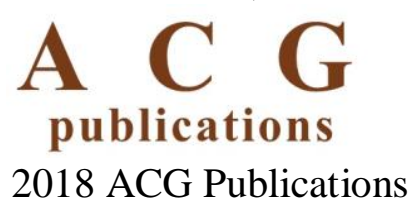

